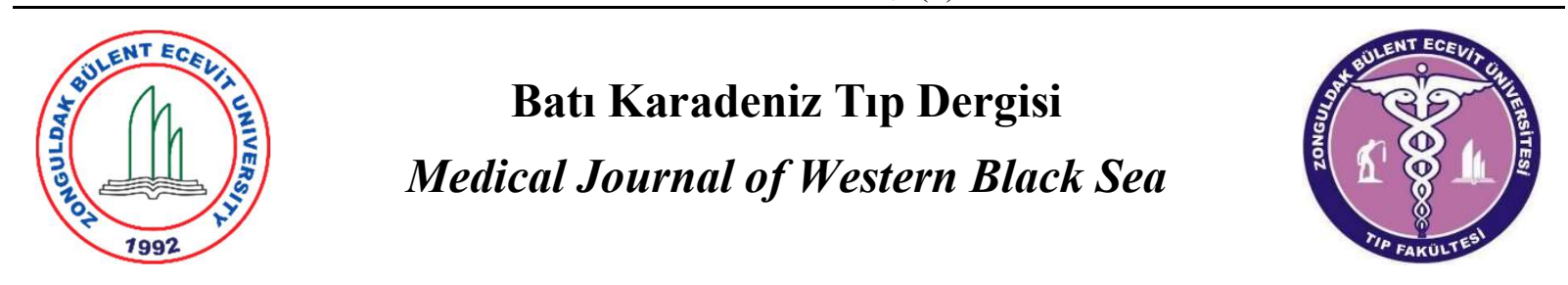

Araştırma Makalesi

Doi: $10.29058 / \mathrm{mjwbs} .2019 .3 .3$

\title{
Çocuklarda Konjenital Böbrek ve Üriner Kanal Anomalisi(CAKUT); Tek Merkez Deneyimi
}

\author{
Atilla Gemici ${ }^{\text {a }}$, Bahriye Atmış ${ }^{\text {a }}$, Raziye Ergün ${ }^{\text {b }}$ \\ ${ }^{a}$ Erzurum Bölge Eğitim ve Araştırma Hastanesi, Çocuk Nefroloji Kliniği, Erzurum, Türkiye. \\ ${ }^{b}$ Erzurum Bölge Eğitim ve Araştırma Hastanesi, Çocuk Ürolojisi Kliniği Erzurum, Türkiye.
}

ORCID : Atilla Gemici 000000029563 6647, Bahriye Atmış 000000021133 4845, Raziye Ergün 0000000159430505

\begin{tabular}{|c|c|}
\hline $\begin{array}{l}\text { M A K A L E } \\
\text { B İ L G İ S I }\end{array}$ & Ö Z \\
\hline $\begin{array}{l}\text { Gönderilme Tarihi: } \\
\text { 17.05.2019 } \\
\text { Revizyon: } \\
26.12 .2019 \\
\text { Kabul: } \\
\text { 30.12.2019 } \\
\text { Sorumlu Yazar: } \\
\text { Atilla Gemici } \\
\text { dratillagemici@hotmail.com } \\
\text { Anahtar Kelimeler: } \\
\text { Konjenital anomali, renal hasar, } \\
\text { çocukluk çağl, üriner sistem }\end{array}$ & 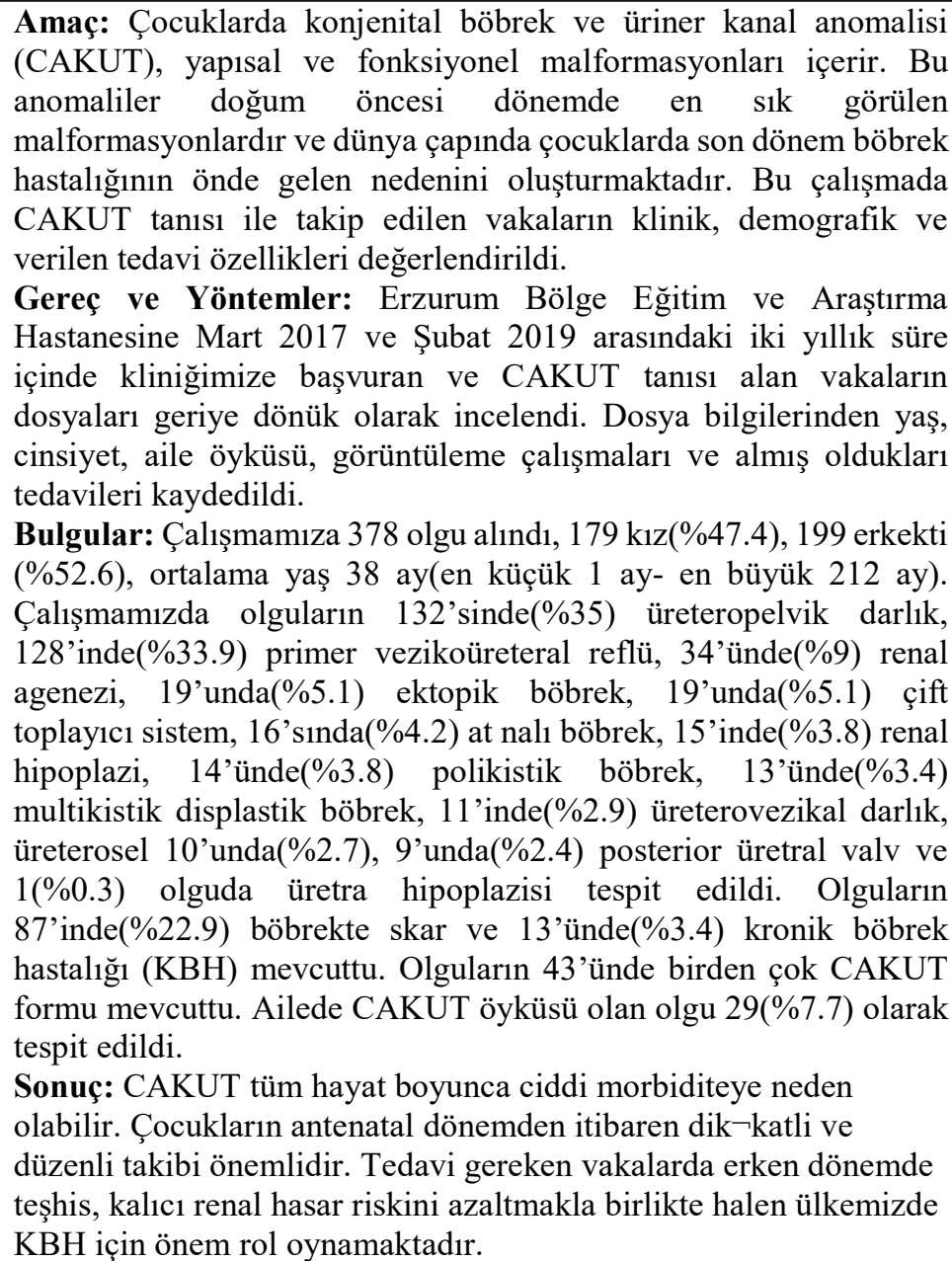 \\
\hline
\end{tabular}




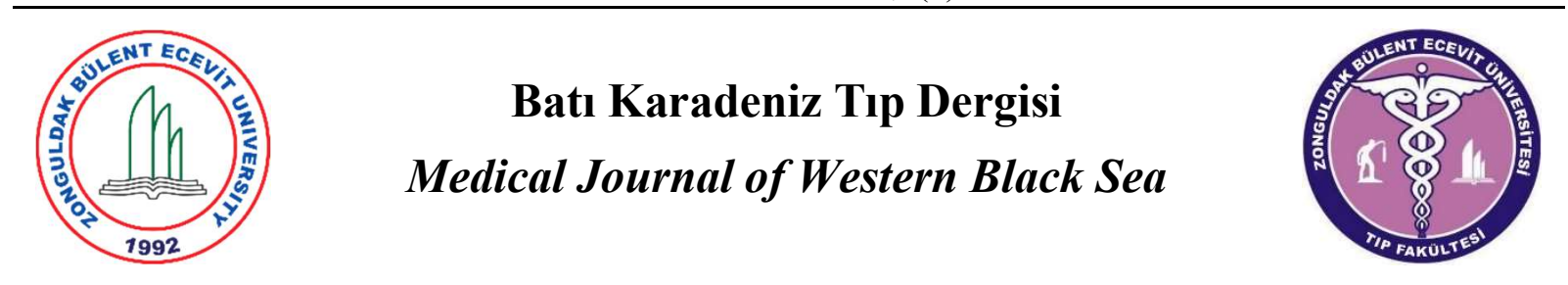

Research Article

Doi: $10.29058 / \mathrm{mjwbs} .2019 .3 .3$

\title{
Congenital Kidney and Urinary Tract Anomalies In Children(CAKUT); Single Center Experience
}

\author{
Atilla Gemici ${ }^{\text {a }}$, Bahriye Atmış ${ }^{\text {a }}$, Raziye Ergün ${ }^{\text {b }}$ \\ ${ }^{a}$ Erzurum Regional Training and Research Hospital, Pediatric Nephrology Clinic, Erzurum, Turkey.. \\ ${ }^{b}$ Erzurum Regional Training and Research Hospital, Pediatric Urology Clinic, Erzurum, Turkey..
}

\begin{tabular}{l} 
A R T I C L E \\
I N F O R M A T I O N \\
\hline Date of Submission \\
17.05.2019 \\
Revision: \\
26.12 .2019 \\
Accepted: \\
30.12.2019 \\
Correspondence Author: \\
Atilla Gemici \\
dratillagemici@hotmail.com \\
\hline KeyWords: \\
Congenital anomaly, renal \\
damage, childhood, urinary \\
system
\end{tabular}

\section{A B S T R A C T}

\begin{abstract}
Aim: Congenital anomalies of the kidney and urinary tract (CAKUT) in children include structural and functional malformations. These anomalies are the most common malformations in the prenatal period and constitute the leading cause of end-stage renal disease in children worldwide. In this study, the clinical, demographic, and treatment characteristics of the children with CAKUT were evaluated.
\end{abstract}

Material and Methods: We retrospectively reviewed the medical records of the children with CAKUT who were admitted to our outpatient clinic during the two years period at Erzurum Regional Education and Research Hospital. Age, gender, family history, imaging studies and treatments were recorded.

Results: The study included 378 patients. $179(47.4 \%)$ children were female, $199(52.6 \%)$ children were males. The mean age was 38 months(min 1 month-max 212 months). In our study, ureteropelvic junction obstruction was detected in $132(35 \%)$ patients, primary vesicoureteral reflux was detected in $128(33.9 \%)$ patients, renal agenesis was detected in 34(9\%) patients, and ectopic kidney was detected in $19(5.1 \%)$ patients, double collecting system was detected in $19(5.1 \%)$ patients, horseshoe kidney was detected in $16(4.2 \%)$ patients, renal hypoplasia was detected in $15(3.8 \%)$ patients, polycystic kidney disease was detected in $14(3.8 \%)$ patients, multicystic dysplastic kidney was detected in $13(3.4 \%)$ patients, uretero-vesical junction obstruction was detected in $11(2.9 \%)$ patients, ureterocele was detected in $10(2.7 \%)$ patients, posterior urethral valve was detected in $9(2.4 \%)$ patients and urethral hypoplasia was detected in one $(0.3 \%)$ patient. Eighty-seven $(22.9 \%)$ patients had renal scar and $13(3.4 \%)$ patients had chronic kidney disease. Forty-three patients had multiple CAKUT forms. Twentynine $(7.7 \%)$ of the patients had a history of CAKUT in the family..

Conclusion: CAKUT may cause serious morbidity throughout life. Careful and regular monitoring of children from the antenatal period is important. Although early diagnosis reduces the risk of permanent renal damage in cases requiring treatment, it still plays an important role in CKD in our country. 
Giriş

Böbrek ve üriner sistemin konjenital anomalileri(CAKUT), böbrek morfogenezisi ve/veya idrar yolundaki kusurlardan kaynaklanan çok çeşitli yapısal malformasyonları içerir (1). Bu yapısal ve fonksiyonel malformasyonlar, kronik böbrek hastalığı olan çocukların yaklaşık \%4050'sini oluşturur ve son dönem böbrek hastalığının en yaygın nedenidir (2,3). Hafif üretero pelvik bileşke darlığı gibi benign anormalliklerinden bilateral renal agenezi gibi yaşamla uyumlu olmayanlara kadar geniş bir sunum yelpazesine sahiptir $(4,5,6)$. Literatürde gebeliklerin \%1'inde anomali saptandığ 1 , bu anomalilerin \%20-30 kadarının genitoüriner sistemde olduğu bulunmuştur (7). Yenidoğanların CAKUT \%0.5'inde bulunur. Ayrıca yenidoğanda tespit edilen abdominal kitlelerin \%50'sini CAKUT oluşturmaktadır. (8). Prenatal 18-20. gestasyonel haftada ultrasonografik inceleme ile bu anomalilerin çoğunluğu tanı almaktadır (9). CAKUT için oligohidroamnioz, böbrek, üreter ve mesane yapısındaki değişiklikler antenatal dönemde sık görülen bulgular iken, doğum sonrası karın muayenesinde ele gelen kitle, beslenme güçlüğü ve idrar çıkışında azalma tanı için uyarıcı bulgulardır. İnsidans ise ölü ve canlı doğan 1000 olguda 0,3 ila 1,6 civarındadır. CAKUT olgularının yaklaşık \%50'sinde alt üriner sistem anomalisi mevcuttur (10). CAKUT insidans1 ABD'de her 1000 canlı doğumda 3-6 olup, olguların tamamına bakıldığında \%34-59'u kronik böbrek hastalığına $(\mathrm{KBH})$ ve \%31'i son dönem böbrek yetmezliğine dönüştüğü görülmektedir. (11). Tüm CAKUT olguları incelendiğinde üriner sistem dilatasyonu \%62 iken, renal kistik dilatasyon 15'ini, diğer alt gruplar \%23'ünü oluşturmaktadır (12). CAKUT ailesel, sendromik olgularda olabilir ve çoğunlukla sporadiktir (7). Tüm CAKUT olgularının \%30’u sendromik olup, genotip ve fenotipdeki çeşitlilik patogenezde çok sayıda faktörün neden olduğunu göstermektedir (13). Erkek ve kızlar arasında görülme sıklığı açısından farklılık yoktur.

Olgularımızın çoğunun başvurduğu Kuzeydoğu Anadolu bölgesinden CAKUT ile ilgili çocuklarda yapılmış çalışma sınırlı sayıdadır. Bu çalışmada Erzurum'da CAKUT tanısı ile izlenen pediatrik vakaların klinik, demografik ve verilen tedavilerin özellikleri sunulmuştur.

\section{Gereç ve Yöntemler}

Erzurum Bölge Eğitim ve Araştırma Hastanesi'nde Mart 2017 ile Şubat 2019 tarihleri arasında Çocuk Nefroloji ve Çocuk Üroloji
Kliniklerinde CAKUT tanısı ile takip edilen hastaların dosyaları retrospektif incelendi. Olguların cinsiyeti, yaşı, ailede üriner sistem anomali öyküsü ve yapılmış görüntüleme çalışmaları kaydedildi. Çalışmamızda renal agenezi, renal hipoplazi, at nalı böbrek, multikistik displastik böbrek(MKDB), polikistik böbrek(PKB), ektopik böbrek, üreteropelvik darlık(UPD), üreterovezikal darlık(UVD), primer vezikoüreteral reflü(VUR), çift toplayıc1 sistem(duplike pelvis), posterior üretral valv(PUV) ve üretra anomalisi tanıları ile izlenen hastalar çalışmaya alınırken, multipl anomalinin eşlik ettiği sendromik olgular çalışma dışı bırakıldı. Üreteropelvik darlığa bağlı hidronefrozlar için Avrupa konjenital anomalileri takip derneğinin (European surveillance of congenital abnormalities/EUROCAT) kabul ettiği, doğum sonrası için $10 \mathrm{~mm}$ ve üstü pelvikalsiyel dilatasyonları olan olgular çalışmaya alındı. Primer VUR için olguların üroflowmetrik incelemesi, işeme bozuklukları semptom skorlaması yapılarak, aşırı aktif mesane ve disfonksiyonel işemeye ikincil olan olgular dışlandı. Olguların etkilenen böbreklerindeki parankim kalınlığında incelme ve/veya skar varlığ ile ilk tanı anında $\mathrm{KBH}$ olan vakalar kayıt altına alındı. Takip süresi içinde cerrahi işlem gerektiren olgular ve UPD'1 olan olgularda parenkimal etkilenme ve pelvis anteroposterior(AP) çapına göre sınıflama yapıldı, bilgileri kayıt altına alındı. Sağlık Bilimleri Üniversitesi Erzurum Bölge Eğitim ve Araştırma Hastanesi Etik Kurulundan 07.01.2019 tarihli Sayı: 37732058-514.10 no ile verilmiştir

\section{Bulgular}

Çalışmamıza 378 olgu alındı, 179'u kız(\%47.4), 199'u erkekti(\%52.6), ortalama yaş 38 (en küçük 1 ay- en büyük 212 ay) aydı. Ailede CAKUT öyküsü $29(\% 7.7)$ olguda tespit edildi. Çalışmamızda olguların 132 'sinde(\%35) üreteropelvik darlık(UPD), 128'inde(\%33.9) primer vezikoüreteral reflü(VUR), 34'ünde(\%9) renal agenezi, 19'unda(\%5.1) ektopik böbrek, 19'unda(\%5.1) çift sistem, 16'sında(\%4.2) at nalı böbrek, 15'inde( $\% 4)$ renal hipoplazi, 14'ünde(\%3.8) polikistik böbrek(PKB), 13'ünde(\%3.4) multikistik displastik böbrek(MKDB), 11'inde(\%2.9) üreterovezikal darlık(UVD), üreterosel 10'unda(\%2.7), 9'unda(\%2.4) posterior üretral valv(PUV) ve $1(\% 0.3)$ olguda üretra hipoplazisi tespit edildi. Olguların 87'inde(\%22.9) böbrekte hasar1 gösteren skar varken, kronik böbrek hastalığı(KBH) 13'ünde(\%3.4) saptandı. Olguların 43'ünde $(\% 11,3)$ birden çok CAKUT formu mevcuttu.(Tablo 1). 
Tablo 1. Vakaların demografik özellikleri ve tespit edilen anomaliler

\begin{tabular}{|lcc|}
\hline & n & \% \\
\hline Erkek & 199 & 52.6 \\
\hline Kız & 179 & 47.4 \\
\hline Ailede CAKUT & 29 & 7.7 \\
\hline UPD & 132 & 35 \\
\hline VUR & 128 & 33.9 \\
\hline Renal Agenezi & 34 & 9 \\
\hline Ektopik Böbrek & 19 & 5.1 \\
\hline Çift Sistem/Duplike Üreter & 19 & 5.1 \\
\hline Atnalı Böbrek & 16 & 4.2 \\
\hline Renal Hipoplazi & 15 & 4 \\
\hline Polikistik Böbrek & 14 & 3.8 \\
\hline Multikistik Displastik Böbr. & 13 & 3.4 \\
\hline UVD & 11 & 2.9 \\
\hline Üreterosel & 10 & 2.7 \\
\hline PUV & 9 & 2.4 \\
\hline Üretra Hipoplazisi & 1 & 0.3 \\
\hline
\end{tabular}

43 olguda birden fazla CAKUT(konjenital böbrek ve üriner kanal anomalisi) grubu mevcuttu. UPD: üretereropelvik darlık, VUR:veziko-üreteral reflü, UVD:Üretero-vezikal darlık, PUV: Posterior üretheral valv

UPD olan 132 olguda erkek/kız oranı 1.75 idi, obstrüksiyon 36 vakada(\%27.2) sağda, 68 vakada(\%51.5) solda, 28 vakada(\%21.2) bilateral izlendi. Olgulardan 37'sinde(\%28) renal parankimde incelme ve 8 'inde(\%6.1) skar ayrica $\mathrm{KBH}$ 2 'sinde(\%1.5) ve yine 2 'sinde(\%1,5) VUR tespit edildi. Cerrahi müdahale uygulanan hasta sayıs1 $33(\% 25)$ idi. Olguların 8 'inde(\%6.1) aile öyküsünde CAKUT mevcuttu.

VUR tespit edilen olgularda erkek/k1z oranı 0.62 idi. VUR, 55 olguda $(\% 42.9)$ bilateraldi, her iki cinsiyette sol VUR ön planda idi ve 72 vakada(\% 56.2) böbrekte skar vardı ve bu oran ile en çok skara sahip olan gruptu. Aile öyküsü 10 olgu(\%7.8) ile CAKUT öyküsü en yüksek oranda saptanan gruptu. Renal agenezi, olguların 20'sinde(\%58.8) sağda, 14 'ünde(\%41.2) solda idi. Erkek/kız oranı 1.26 idi. İki olguda VUR en sık eşlik eden anomaliydi. Aile öyküsünde bir olguda(\% 2.94) CAKUT vardı. Skar bir olguda(\%2.94) saptand1. İki olgu(\%5,9) KBY ile takipli idi.

Ektopik böbrek, olguların 11'inde(\%58) sağda idi. Erkek/kız oranı 0.58 idi. Ek anomali olarak iki olguda VUR tespit edildi. Pozitif aile öyküsü yoktu. Çift toplayıcı sistem saptanan 19 olgudan 11'inde (\%58) sol çift toplayıcı sistem mevcuttu. Erkek/kız oranı 0.26, ek anomali en s1k dört olguda VUR ve dört olguda üreteroseldi. Böbrekte skar yedi olguda gelișmiști. Olguların 10’u (\%52) cerrahi müdahale gerektirdi.

At nalı böbrek saptanan vakaların erkek/kız oranı 0.6 idi. Bir olguda çift sistem, 3 olguda UPD ve özellikle 1 olguda bilateral obstrüktif UPD tespit edildi. Aile öyküsü saptanmadı.

MKDB'li olguların 8'inde(\%61.5) sağda MKDB tespit edildi. Erkek/kız oranı 2,25 idi. Aile öyküsü saptanmazken, olguların birinde diğer böbrekte skar saptand1. Eşlik eden diğer anomaliler bir olguda üreterosel, bir olguda VUR, bir olguda nonobstrüktif UPD saptandi.

PKB'li vakalarda erkek/kız oranı 0.55 idi. Olguların beşinde $(\% 35.7)$ otozomal dominant PKB, 9'unda(\%64.3) otozomal resesif PKB tespit edildi. Aile öyküsünde yedi olguda(\% 50) PKB hastalı̆̆ mevcuttu. Olguların 2'sinde(\%14.3) tanı anında $\mathrm{KBH}$ tespit edildi. PUV'li olguların tamamına cerrahi tedavi uygulanmıştı. Beşinde(\%55.5) KBH tespit edildi. Bu grup tüm CAKUT olgularının içinde $5 / 13(\% 38.5)$ olgu ile en yüksek oranda $\mathrm{KBH}$ nedeniydi. VUR 4/13(\%30.8) olgu ile ikinci sirada KBH'ya yol açmakta idi.

\section{Tartışma}

Böbrek ve idrar yollarının konjenital malformasyonları, tüm doğum kusurlarının \%23'ünü temsil eder. Yenidoğanlarda saptanan abdominal 
kitlelerin ise yaklaşı1k \%50'sini CAKUT oluşturur. İnsidans ise canlı doğan 1000 olguda 3 ila 6'dır. Gelişmiş görüntüleme yöntemlerinin son zamanlarda antenatal taramalarda sık kullanılması ile CAKUT insidansında da artış izlenmektedir. Çocuklarda CAKUT'un morbiditesi yüksektir ve son dönem böbrek yetmezliği olguların \%30 ila $\% 50$ 'sinde gelişebilir $(10,14)$. CAKUT ise dünya çapındaki yetişkin son dönem böbrek hastalığının \%7'sini oluşturur. $\mathrm{Bu}$ malformasyonlar arasında renal aplazi, agenezi, hipoplazi ve displazi, uzun süreli böbrek sağ kalımı üzerine derin bir etkisi olan ciddi hastalık formlarını temsil eder $(3,15,16)$. CAKUT gruplarının KBH'ye girip girmedikleri ve SDBY'ne girme hızları farklılık gösterir. $\mathrm{Bu}$ olguların SDBY'ne erişkin dönemde önemli bir kısmı girmektedir. $\mathrm{Bu}$ nedenden dolayı çocukluk çağındaki takipler önemlidir (17). Konjenital anomalilerin çoğunda olduğu gibi multipl genler, çevresel faktörler, embriyo ve fetüs gelişimini etkiler ve CAKUT gelişimine yol açarlar (11).

Obstrüktif CAKUT ülkemizde yapılan çok merkezli bir çalışmada, çocuklardaki KBH'nın etyolojisinde \%10,7 oranında rol oynadığı bildirilmiştir (18). İnfant ve çocuklardaki KBH'nın bilinen en önemli nedenlerinden biridir. UPD; hidronefroz ve üreterin konjenital anomalilerinin, yenidoğanda ve çocukluk döneminde en sık sebebidir. Fetal dönemdeki en s1k görülen anomalidir ve tüm gebeliklerin \%1-5'inde görülür $(5,19)$. CAKUT'un \%50'sini oluşturur (20). İdrar yolunun ciddi anomalisinin \%0,2'sini oluşturur. Canlı doğumların 2000'de1'inde görülen bu hastalık erkeklerde k1z olgulara göre iki kat daha fazla görülür. UPD'nin \%60’1 geçici ve fizyolojikken, bilateral saptanma oranı \%20-40 arasinda değişmektedir. Çoğunlukla tek taraflı ve sağa göre yaklaşı 2-2,5 kat daha fazla sol böbrekte görülmektedir. Müspet aile hikayesi olguların \%8'inde vardır (20). Çalışmamızda da en sık gözlenen anomali UPD'dır ve erkek olgularda daha fazla saptanmıştır. Ayrıca sol böbrekte obstrüksiyon \%51,5 olarak tespit edilmiştir. Cerrahi tedavi UPD tanısı ile takipli olguların \%10-25'ine gerekir (21). Cerrahi tedavi gerektiren olgularımız $\% 25$ oranındadır. $\mathrm{Bu}$ oran literatür ile benzerdi. Retrospektif olarak Brezilya'da yapılan 822 hastayı içeren bir çalışmada doğum öncesi CAKUT tespit edilen olgular incelenmiştir. Postnatal dönemde olgularda en sik saptanan anomalinin idiopatik hidronefroz \%37.5 iken; UPD'nin \%19 olduğu, takip sürecinde ise UPD olan olgularda uzun dönemde KBH \%18,4'ünde geliştiği bildirilmiştir (22). Araştırmamızda UPD oranı \%34.9 idi ve bu çalışmayla kısmen benzerdi. Olgularımızın \% 6'sında renal skar ve 2 vakada $\mathrm{KBH}$ tespit edilmişti ve bu bulgular literatür ile benzer değildi.

VUR, idrarın retrograd olarak mesaneden böbreğe akışı olarak tanımlanır. Primer VUR en sık üreterin kısa intravezikal seyrinden kaynaklanır, bu durum valf mekanizmasını etkiler, neticesinde üreterlere kaçak gelişir. Primer VUR 'de çocuk büyüdükçe üreter uzar ve VUR derecesi azalır. İleri derecede VUR'de spontan rezolüsyon nadirdir. $\mathrm{Bu}$ olgularda tekrarlayan idrar yolu enfeksiyonu(IYYE) sıklıkla görülür ve fonksiyon kaybı ile giden kalıcı böbrek hasarına yol açabilir. VUR insidansı her iki cinsiyette de aynıdır (100 yenidoğandan 1'i) (23). Hidronefrozlu yenidoğanlarda prevalans yaklaşık \%15'tir. Ailesel VUR olgularının bir kısmi ROBO2 isimli gendeki mutasyon ile ilişkilendirilmiştir (24). $\mathrm{Bu}$ çalışmamızda olgularımızın 128'inde (\%33.9) primer VUR tespit ettik. CAKUT olgularımızda VUR ikinci en sık saptamış olduğumuz anomaliydi ve en sık bilateral VUR saptadık. Elmacı ve ark. 232 olguyu içeren 2014 yılında yayımlanan çalışmalarında, renal ageneziyi 2 . sıklıkta saptamışlardır ve bu veri bizim çalışmamız ile uyumsuzdu. Ülkemizde son yıllarda yayımlanan bu çalışma ile benzer bulgu saptamamış olmamızı; olgularımızın düzenli takip yaptırmamasına ve bunun sonucu olarak ileri düzeyde incelemelerin gecikmesinin bir sonucu olabileceğine bağladık. Elmacı ve ark.'nın çalışmasının bulgularının aksine Bulum ve ark.'nın akraba olmayan ailelerden olan 213 olguyu içeren çalışmalarında, VUR en sık görülen anomaliydi(\%42.7). Bu çalışma ve bizim çalışmamızdaki özellikle adölesan yaş grubunda tespit etmiş olduğumuz VUR olguları; klinisyenlerin tekrarlayan İYE'nun altında patoloji olabileceği farkındalıklarının halen zayıf olduğunu düşündürmekte ve düzenli takip ile yerinde yapılan ek incelemeler VUR'nün halen yüksek oranlarda saptandığını ortaya koymaktadır (14). Çalışmamızda KBY olan olgularımızda sıklık açısından 2. sırada VUR olması, bölgemiz için SDBY'de halen önemli CAKUT nedenlerinden biri olduğunu göstermektedir.

Doğuştan her iki veya tek böbreğin olmaması Renal agenezi(RA) olarak tanımlanmaktadır. Embriyolojik dönemde renal mezenkim hücreleri gelişmemesi ile böbrek oluşamaz. Bilateral böbrek agenezisi neredeyse her zaman yaşamla uyumlu değildir. Bilateral RA 4500 canlı doğumda 1 görülmektedir (25). Tek taraflı böbrek agenezisinin görülme sıklığı \%0,05'tir (26). Kızlara göre erkek olgularda RA daha sıktır. Bu olgularda aile hikayesi saptanmamasına rağmen; \%20'sinde genetik sebep saptanmıştır. RA ihtimali eğer ailede hikaye varsa 
\%15'e kadar çıkmaktadır (26). Prognoz RA'de diğer böbreğin durumuna, ek anomaliler varsa(UPD, UVD, VUR vb) ve ciddiyetine bağlıdır. Takipte hipertansiyona ve böbrek yetmezliğine dikkat edilmelidir. VUR'ye eşlik eden tekrarlayan IYE ve böbrek taşı diğer komplikasyonlardır (26). Tüm bunlar göz önüne alındığında RA'li çocuk olgular KBH için takibe alınmalıdır (26). RA'li olgularında Westland ve ark.'nın yapmış oldukları bir çalışmada renal hasarı değerlendirmek için takibe almışlar. Takipli RA'li olgularında hipertansiyon ve albuminüri varlığı ile uzun dönemde gelişen renal hasarı araştırmışlardır (27). Bu çalışmada primer RA'li olgularından \%63'ü erkekti ve tüm olgularının $\% 26$ 'sında eşlik eden diğer CAKUT fromlarını tespit etmişlerdi. Çalışmalarının sonucunda tüm olguların \%32'sinde renal hasar bildirilmişlerdir. Çalışmamızda da RA erkeklerde daha sıktı. Vakaların \%14,7'sinde eşlik eden bir CAKUT tespit edildi. Renal agenezi olan hastalardan sadece ikisinde KBY vard.

Renal ektopi insidans1 1000 otopside 1'dir (28). Tanım olarak böbreğin normal bulunması gereken yer olan renal fossa dışında olmasına ektopik böbrek denmektedir ve en sık pelvik yerleşimlidir. Olguların \%10'u çift taraflıdır (29). Her 900 canlı doğumda 1 görülür (30). Elmacı ve ark. çalışmalarında renal ektopiye ek anomali olarak renal agenezi tespit edilmişti (31). Çalışmamızda ayrıca VUR'de tespit edildi. Bu bize ektopik böbreği olan olguların özellikle eşlik eden CAKUT için araştırılması gerektiğini göstermektedir.

Çift sistem(Üreter duplikasyonu) toplayıcı sistemin en sik rastlanan siklikla klinik bulgu vermeyen anomalisidir. Yapılan 160 otopside 1 rastlanmaktadır. Kızlarda erkeklere göre daha fazla görülür. Rutin ya da başka nedenle istenen radyolojik görüntülemelerde $\% 0,9$ oranında tespit edilir ve klinik bulgu vermeyebilir. (32). Çalışmamızda da oranlar literatürdekine benzerdi ve \%79 oranında en sık görüldüğü cinsiyet kız olgulard1.

Kaynaşmış veya at nalı böbrek insidansı 10.000 canlı doğumda 0,4 ila 1,6'dır (33). At nalı böbrek bu grupta şekil anomalisi olarak en sık görülen CAKUT olup, kızlara göre, erkeklerde iki kat daha sıktır. Bu olgularda VUR, UPD gibi diğer sistem anomalileri de eşlik yaklaşık \%30 oranında eşlik eder. Böbreğin şekil ve pozisyon anomalileri hastanın yaşam süresini etkilemez. Olgularımızın $\% 25$ 'ine eşlik eden CAKUT tespit edildi ve bu bulgu literatür ile benzerdi.
Böbreğin en sık görülen kistik hastalığı MKDB'dir. Canlı doğan 4300 bireyden 1 olguda görülür. Prenatal olarak tespit edilen vakalarının \%20'sini bilateral MKDB oluşturur (34). MKDB'li olguların \%55'inde sol, \%45'inde sağ böbrek etkilenirken; tüm olguların \%50'sine diğer sistem anomalileride eşlik eder. UPD ve VUR diğer böbrekte en sık görülen toplayıcı sistem anomalisidir. Hipertansiyon, böbrek boyutunda artış ve malignite gelişimi açısından displastik olan böbrek nedeniyle uzun dönemde takip gereklidir. Literatürde ülkemizde yapılan 102 MKDB'li olguyu içeren bir çalışmada erkek/kız oranı 1.5:1 bulunmuş ve 96 hastanın uzun dönem takibinde, bir hastada hipertansiyon tespit edilmiş ve malignite saptanmamıştır (35). Araştırmamızda bu çalışmaya benzer şekilde erkek/kız oranı $2.25^{\prime}$ di. MKDB'li olgularımıza en çok eşlik eden anomali VUR'dür (36). Çalışmamızda da iki olguda MKDB'e eşlik eden ek üriner sistem anomalisi olarak VUR tespit edilirken, diğer böbrekte UPD tespit edilmiştir.

Posterior üretral valf(PUV)'in erkek çocuklarda görülmesinin nedeni, anatomik bozukluğa yol açan valflerin veru montarumdan köken almasıdır. Kız çocuklarda veru montarum hymene dönüşür, bundan dolay1 erkeklerdeki gibi üretra obstrüksiyonu gelişmez. Olguların 1/3'ünde erişkin çağa ulaşmadan $\mathrm{KBH}$ gelişir ve renal replasman tedavisi gerekir (10). İnsidans olarak 4000 canlı erkek doğumda 1 görülmekle birlikte, olguların tespiti $\% 8$ 'i intrauterin, \% 34'ü yenidoğan döneminde, \% 32'si ilk bir yaşta, \% 25' i ise bir yaşından sonrası ve ülkemiz için adölesan dönem sonrasına kadar gecikebilmektedir $(37,38)$. İntrauterin ilk 20 haftada PUV olan olgularda, VUR'ye sekonder olarak gelişen renal hasara ve ciddi renal displaziye neden olur. Literatürde 52 PUV'li olguyu içeren, Kibar ve ark. tarafindan yapılan bir çalışmada, erken ve geç tanı alan vakalar arasında uzun dönem takiplerinde KBH hastalığı gelişimi açısından anlamlı fark olmadığını bildirmişlerdir (39). Yine literatürde Gargah ve arkadaşlarının 44 PUV tanılı olguyla yaptıkları çalışmada; olgularının ortalama yaşının 2 olduğu, ayrıca 36 'sının $(\% 81,8)$ KBY'de olduğu bildirmişlerdir (40). Araştırmamızda PUV'li grubun en kötü prognoza sahip olduğunu, KBY'ne diğer CAKUT gruplarına göre çok daha erken yaşta girdiğini söyleyebiliriz. Araştırmamızda cerrahi müdahale yapılan grup PUV'(\%88) idi.

Literatürde ülkemizde yapılan bir çalışmada, CAKUT tanısı ile izledikleri olgularının \%22,9'unda müspet aile öyküsü ve $\% 24,8$ 'inde akraba evliliği bildirilmiştir (14). Bu çalışmada 180 vakanın, bilinen ürolojik problemi olmayan 1. derece 
akrabaları incelenmiş ve \% 48,3 'ünde CAKUT tespit edilmiştir. Fakat araştırmamızda aile öyküsü \%7.7'sinde mevcuttu. Çalışmamızda aile öyküsünün beklenenden düşük çıkması CAKUT saptanan vakaların tüm aile bireylerine tarama yapılamamasına ve ailelerin yanıtlarında netlik olmamasına bağlamaktayız.

Özellikle araştırmamızda primer VUR olgularında, sık tekrarlayan IYE'nda düzensiz takip yapıldığı ve klinisyenlerin çocuk nefroloji-üroloji derneklerince önerilen kılavuzları uygulamadıkları görüldü. $\mathrm{Bu}$ nedenlerden dolayı VUR'lü olguların tanısının geciktiğini söyleyebiliriz.

Çalışmamızda kısıtlılıklar, CAKUT olgularının ebeveynlerinin akraba evliliği sorgulaması yapılmaması, ailelerin pozitif aile öyküsü için verdikleri yanıtların eksik olduğunu düşündüren yetersiz cevaplarıyd.

Sonuç olarak, çocukluk çağı son dönem böbrek yetmezliğinin (SDBY) en önemli nedenlerinin başında CAKUT gelmektedir. CAKUT başlığı altında olan grupların KBY ve SDBY geliştirme hızları farklılıklar göstermektedir. Bu bulguların 1şığında CAKUT vakalarının birçoğunda kalıcı renal hasar gelişimi, antenatal dönemde ve yaşamın ilk yıllarında uygun görüntüleme yöntemleri kullanılarak yapılan sistemli yaklaşım ile önlenebilir. Fakat geç yaşta tanı konulan CAKUT olguları nedeni ile gelişen KBH'nın, tüm SDBY'leri içinde halen en yüksek oranda yer almasına yol açmaktadır. Bu durum CAKUT için klinisyenlerin farkındalığının artırılması gerekliliğini ortaya koymaktadır.

\section{Kaynaklar}

1.Schedl A. Renal abnormalities and their developmental origin. Nat Rev Genet. 2007;8:791802 .

2. Hildebrandt F. Genetic kidney diseases. Lancet 2010;375:1287-1295.

3. Harambat J. et al. Epidemiology of chronic kidney disease in children. Pediatr Nephrol. 2012;27:363373 .

4. Wiesel A. et al. EUROSCAN Study Group. Prenatal detection of congenital renal malformations by fetal ultrasonographic examination: an analysis of 709,030 births in 12 European countries. Eur J Med Genet. 2005;48(2):131-144.
5. Livera LN. et al. Antenatal ultrasonography to detect fetal renal abnormalities: a prospective screening programme. BMJ. 1989;298(6685):14211423.

6. Caiulo VA. et al. Ultrasound mass screening for congenital anomalies of the kidney and urinary tract. Pediatr Nephrol. 2012;27(6):949-953.

7. A. Daneman and D. J. Alton. Radiographic manifestations of renal anomalies.Radiologic Clinics of North America 1991;29:351-363.

8. Scott JE, Renwick M. Antenatal diagnosis of congenital abnormalities in the urinary tract. Results from the Northern Region Fetal Abnormality Survey. Br J Urol. 1988;62:295-300.

9. Miyazaki Y. et al. Bone morphogenetic protein 4 regulates the budding site and elongation of the mouse ureter. J Clin Invest 2001;105:863-873.

10. Rosenblum ND, Salomon R. Disorders of kidney formation. In: Geary DF, Schaefer F (eds). Comprehensive Pediatric Nephrology. MosbyElsevier, Philadelphia, 2008;132-141.

11. Yosypiv IV Congenital anomalies of the kidney and urinary tract: a genetic disorder? Int J Nephrol 2012; 2012:909083 doi: 10.1155/2012/909083.

12. Chen F. Genetic and developmental basis for urinary tract obstruction. Pediatr Nephrol 2005;24:1621-1632.

13.K. Nakanishi, N. Yoshikawa. Genetic disorders of human congenital anomalies of the kidney and urinary tract (CAKUT), Pediatrics International $2003 ; 5: 610-616$.

14. Bulum B, Ozçakar ZB, Ustüner E, Düşünceli E, Kavaz A, Duman D, et al. High frequency of kidney and urinary tract anomalies in asymptomatic firstdegree relatives of patients with CAKUT. Pediatr Nephrol 2013;28:2143-2147.

15. Seikaly MG. et al. Chronic renal insufficiency in children: the 2001 Annual Report of the NAPRTCS. Pediatr Nephrol. 2003;18(8):796-804.

16. Loane M. et al. EUROCAT Working Group. Paper 4: EUROCAT statistical monitoring: Identification and investigation of ten year trends of congenital anomalies in Europe. 2011 Birth Defects Res A Clin Mol Teratol. 91 Suppl 1:S31-43. 
17. Wühl E. et al. Timing and outcome of renal replacement therapy in patients with congenital malformations of the kidney and urinary tract. Clin J Am Soc Nephrol 2013 Jan;8(1):67-74.

18. Şimşek F, Tinay İ. Çocuklarda üretero-pelvik bileşke obstrüksiyonları. Klinik Gelişim 2008;21:24-27.

19. Gunn TR. et al. Antenatal diagnosisof urinary tract abnormalities by ultrasonography after 28 weeks gestation: incidance and outcome. Am J Obstet Gynecol 1995;172:479-486.

20. Liang CC. et al. Outcome of prenatally diagnosed fetal hydronephrosis. J. Reprod. Med. 2002; 47:27-32.

21. Ulman İ, Divarcı E. Çocuklarda obstrüktif üropatiler. Türk Ped Arş 2010;45:85-89.

22. Quirino IG. et al. Clinical course of 822 children with prenatally detected nephrouropathies. Clin J Am Soc Nephrol 2012;7:444-451.

23. Dillon MJ, Goonasekera CD. Reflux nephropathy. J Am Soc Nephrol. 1998;9(12):23772383.

24. Lu W. et al. Distrution of ROBO2 is associated with urianary tract anomalies and cinfers risk of vesicourethral reflux. Am J Hum Genet 2007;80:616-632.

25. Rajesh Yalvarthy, Chirag R Parikh. Congenital renal agenesis Suudi Journal of Kidney Disease and transplantation 2003;14:336-341.

26. Westland R. et al. Unilateral renal agenesis: a systematic review on associated anomalies and renal injury. Nephrol Dial Transplant. 2013;28(7):18441855.

27. Westland R. et al. Renal injury in children with a solitary functioning kidney--the KIMONO study. Nephrol Dial Transplant 2011;26:1533-1541.

28. Yuksel A, Batukan C. Sonographic findings of fetuses with an empty renal fossa and normal amniotic fluid volume. Fetal Diagn Ther.2004;19(6):525-532.

29. David G, Botswick Liong Cheng. Urologic surgical pathology 2008;323:1970-1975.
30. Bauel SB, Wein A. Anomalies of upper urinary tract; Campell-Walsh Urology 2007;17:3269-3304.

31. Elmacı A. M., Akın F. Clinical and demographic characteristics of children with congenital anomaly of kidney and urinary tract Dicle Medical Journal. 2014;41(2):309-312.

32. Nordmark B. Double formation of the kidneys and ureters, embryology, occurance and clinical significans. Acta Radiol. 1948;30:276-278.

33. Schulman J. et al. Surveillance for and comparison of birth defect prevalences in two geographic areas: United States, 1983-88. MMWR CDC Surveill Summ. 1993;42(1):1-7.

34. Numanoğlu Yurdakan G. Et al. Renal hypoplastic dysplasia. OMÜ Tıp dergisi; 2008;25(1):25-29.

35. Tiryaki S. et al. Involution of multicystic dysplastic kidney: is it predictable? J Pediatr Urol 2013;9:344-347.

36. Becker AM. Postnatal evaluation of infants with an abnormal antenatal renal sonogram. Curr Opin Pediatr 2009;21:207- 213.

37. Martin I. Resnick, Robert A. Older. Diagnosis of genitourinary disease; second edition, 1997; 573577.

38. Grigoris C, Kousidis. Posterior Urethral Valve; Essential in Pediatric Urology; 2012; 115-124.

39. Kibar Y. et al. Timing of posterior urethral valve diagnosis and its impact on clinical outcome. J Pediatr Urol 2011;7:538-542.

40. Gargah T. et al. Posterior urethral valves: About a series of 44 cases Tunis Med 2010; 88(8):557-562. 